\title{
Corrosivity of Molten Alkali and Alkaline Earth Carbonate to SUS 310 S under a Simulated MCFC Cathode Environment
}

\author{
Kazumi TANIMOTO*, Yoshinori MIYAZAKI, Masahiro YANAGIDA, Shigeo TANASE \\ Toshikatsu KOJIMA, Norikazu OHTORI and Teruo KODAMA
}

Received June 10, 1993 ; Accepted November 4, 1993

\section{INTRODUCTION}

A molten carbonate fuel cell (MCFC) is being developed to be commercialized as an attractive electric power generation. The endurance of MCFC should be improved to that purpose. The authors have investigated the effect of the addition of alkaline earth carbonate $\left(\mathrm{CaCO}_{3}\right.$, $\mathrm{SrCO}_{3}$ and $\mathrm{BaCO}_{3}$ ) to the typical carbonate mixture $\left(\mathrm{Li}_{2} \mathrm{CO}_{3} / \mathrm{K}_{2} \mathrm{CO}_{3}: 62 / 38 \mathrm{~mol} \%\right)$ on endurance of the MCFC. We reported that these additions reduced the solubility of nickel oxide in the carbonate mixtures 1). They are expected to be beneficial process. Te corrosivity of alkali and alkaline earth carbonate mixtures to the MCFC components, however, is not known in detail. Before the application of these carbonate mixtures to MCFC electrolytes, the effect of addition of alkaline earth carbonate to the alkali carbonate on the corrosivity of carbonate mixtures has to be examined. In the present work, the corrosivity of carbonate mixtures to type $310 \mathrm{~S}$ stainless steel (SUS 310S) was examined, since SUS $310 \mathrm{~S}$ is typically used for the separator plate 2) which is the most sensitive to corrosion in the MCFC $3 \sim 6$ ). This report describes the corrosivity of the alkali and alkaline earth carbonate mixtures to SUS 310 S under a simulated MCFC environment.

The separator plate acts as an electrical connector between unit cells and as a gas dis-

Osaka National Research Institute, AIST (Midorigaoka 1 8 -31, Ikeda, Osaka 563, Japan)

Key Words: Molten Carbonate, Fuel Cell, Alkaline Earth Carbonate tributor. In the stacked MCFC, unit cells are connected in series by the separator plate which carries the electrical current. Each side of the separator plate is exposed to the different gas atmospheres on different sides. One side is exposed to oxidizing gas, the other side to reducing gas. In the present investigation, the environment of the separator plate was simulated to represent normal MCFC condition. The corrosivity of the carbonate mixtures was evaluated on the oxidizing gas side only, since the corrosion behavior of SUS 310S on this side has been well known for the typical carbonate 7 ).

\section{EXPERIMENTAL}

\subsection{Test assembly}

To obtain a good simulation of separator plate environment in the MCFC, the dual atmosphere method which was developed by Illinois Institute of Technology Research Institute was applied 2). A test assembly is shown in Fig. 1. The test assembly consisted of a separator plate, green matrix tapes, green carbonate mixture tapes and holders. The separator plate was made of SUS 310S, of which composition is shown in Table 1. The plate was $2 \mathrm{~mm}$ thick and $50 \mathrm{~mm}$ in diameter. Both surfaces were polished using $\mathrm{SiC}$ paper, finished with diamond (6 microns) paste and washed with distilled water and acetone. A matrix was fabricated from $80 \mathrm{wt} \% \gamma-\mathrm{LiAlO}_{2}$

Table 1 Chemical composition of SUS 310S.

\begin{tabular}{cccccccc}
\hline Element & $\mathrm{C}$ & $\mathrm{Si}$ & $\mathrm{Mn}$ & $\mathrm{P}$ & $\mathrm{S}$ & $\mathrm{Ni}$ & $\mathrm{Cr}$ \\
\hline $\mathrm{wt} \%$ & 0.04 & 0.81 & 1.22 & 0.013 & 0.001 & 19.18 & 25.06 \\
\hline
\end{tabular}




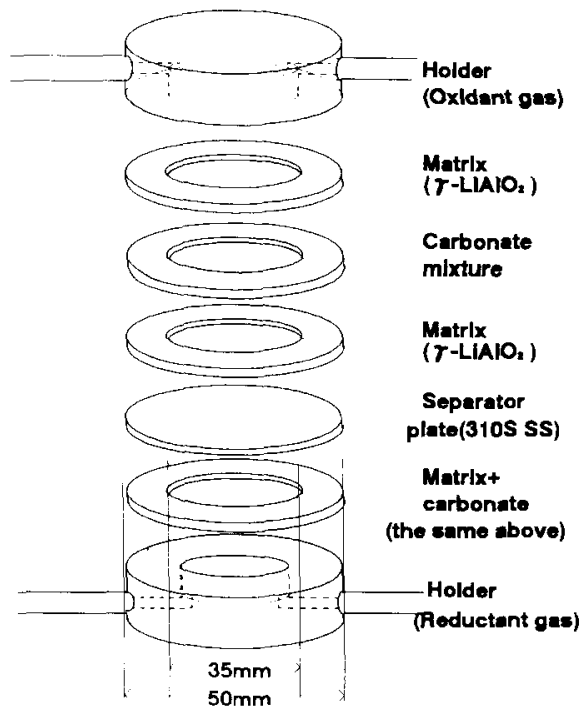

Fig.1 The overview of test assembly.

and $20 \mathrm{wt} \%$ alumina fiber used as reinforcing materials. The green matrix and carbonate mixture tapes were cast from a methanol slurry with an organic binder. After drying, the matrix and carbonate tapes were cut into the ringshaped tapes, shown in Fig. 1. The ratio of carbonate volume to pore volume of matrix was adjusted to $120 \%$. The weight of carbonate mixtures was about $1.8 \mathrm{~g}-2.2 \mathrm{~g}$. The matrix was impregnated with the carbonate mixtures during the heating process. The compositions of the carbonates tested are shown in Table 2. In this report, the notation of the carbonate mixtures are also shown in Table 2. The holders were also made of SUS $310 \mathrm{~S}$.

\subsection{Simulated corrosion test}

The test assembly was put in an electric furnace, which was equipped with the compression equipment. The test assembly was maintained under a compressive force of $2-3 \mathrm{~kg} / \mathrm{cm}^{2}$ using an air pressured piston. During heating, air with flow rate of $c a .200 \mathrm{ml} / \mathrm{min}$ was introduced into both sides of the separator plate to remove the organic binder. The test assembly was maintained at $450^{\circ} \mathrm{C}$ for 3 hours to completely remove the organic binder. After then, carbon
Table 2 Composition of tested carbonate.

\begin{tabular}{lll}
\hline \multicolumn{1}{c}{ Notation } & \multicolumn{1}{c}{ Composition } & \multicolumn{1}{c}{ mol ratio } \\
$\mathrm{Li} / \mathrm{K}$ & $\mathrm{Li}_{2} \mathrm{CO}_{3} / \mathrm{K}_{2} \mathrm{CO}_{3}$ & $1.00(62 / 38)$ \\
$\mathrm{Li} / \mathrm{K} / \mathrm{Ca}$ & $\mathrm{Li}_{2} \mathrm{CO}_{3} / \mathrm{K}_{2} \mathrm{CO}_{3} / \mathrm{CaCO}_{3}$ & $0.91(62 / 38) / 0.09$ \\
$\mathrm{Li} / \mathrm{K} / \mathrm{Sr}$ & $\mathrm{Li}_{2} \mathrm{CO}_{3} / \mathrm{K}_{2} \mathrm{CO}_{3} / \mathrm{SrCO}_{3}$ & $0.91(62 / 38) / 0.09$ \\
$\mathrm{Li} / \mathrm{K} / \mathrm{Ba}$ & $\mathrm{Li}_{2} \mathrm{CO}_{3} / \mathrm{K}_{2} \mathrm{CO}_{3} / \mathrm{BaCO}_{3}$ & $0.91(62 / 38) / 0.09$ \\
$\mathrm{Li} / \mathrm{Na}$ & $\mathrm{Li}_{2} \mathrm{CO}_{3} / \mathrm{Na}_{2} \mathrm{CO}_{3}$ & $1.00(52 / 48)$ \\
$\mathrm{Li} / \mathrm{Na} / \mathrm{Ca}$ & $\mathrm{Li}_{2} \mathrm{CO}_{3} / \mathrm{Na}_{2} \mathrm{CO}_{3} / \mathrm{CaCO}_{3}$ & $0.96(52 / 48) / 0.04$ \\
$\mathrm{Li} / \mathrm{Na} / \mathrm{Sr}$ & $\mathrm{Li}_{2} \mathrm{CO}_{3} / \mathrm{Na}_{2} \mathrm{CO}_{3} / \mathrm{SrCO}_{3}$ & $0.96(52 / 48) / 0.04$ \\
$\mathrm{Li} / \mathrm{Na} / \mathrm{Ba}$ & $\mathrm{Li}_{2} \mathrm{CO}_{3} / \mathrm{Na}_{2} \mathrm{CO}_{3} / \mathrm{BaCO}_{3}$ & $0.96(52 / 48) / 0.04$ \\
\hline
\end{tabular}

dioxide was introduced into both sides and the test assembly was heated to $650^{\circ} \mathrm{C}$. The matrices were impregnated with the carbonate mixture as the temperature passed through the melting point, $490-510^{\circ} \mathrm{C}$, of the carbonate mixtures.

After heating to $650^{\circ} \mathrm{C}$, oxidizing gas and reducing gas were introduced into respective compartments of the test assembly. Oxidant gas was air/carbon dioxide:70/30 vol\% and reducing gas was hydrogen/carbon dioxide:80/20 vol\% (dry base). The reducing gas saturated with $50^{\circ} \mathrm{C}$ water was introduced into the test assemblies by passing through a water-reservoir maintained at $50^{\circ} \mathrm{C}$ to avoid the carbon deposition in the inlet pipe. Two test assemblies were used with each carbonate composition and were held at $650^{\circ} \mathrm{C}$ for 2000 hours and 4000 hours, respectively. At the end of tests, it was confirmed that no gas leakage was observed by gas chromatography.

\subsection{Post - test analysis}

In the present analysis we divided the plate surface on the oxidizing gas side into two regions

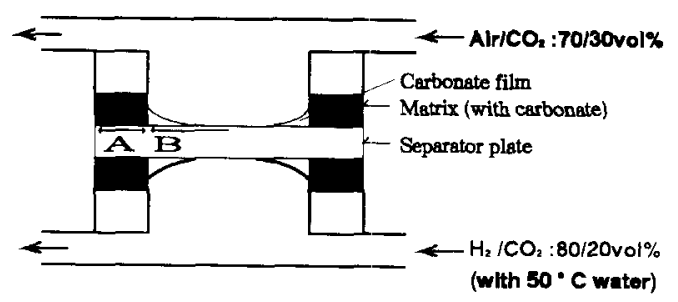

Fig. 2 The cross section schematic diagram of the separator plate exposed to the matrix impregnated with molten carbonate. (A) wet seal region, (B) soaked region. 
depending on the amount of molten carbonate as shown in Fig. 2. At the wet seal region (A) the separator plate was exposed to a large amount of carbonate. At the soaked region (B) it was exposed to a film of carbonate and oxidizing gas diffused through the film. The amount of carbonate mixtures at the soaked region could not be controlled well in these test because it depended on the surface tension and the contact angle of the molten carbonate mixtures. In the contrary, the exposure condition in the wet seal region could be defined in these test. The amount of the carbonate in the wet seal region was more uniform. Furthermore, it was the most corroded region of the separator plate in operating $\mathrm{MCFC}^{3}$ 6). Hence, the corrosivities of carbonate mixtures were quantitatively evaluated in the wet seal region.

The circular part of an unwashed separator plate was embedded halfway into epoxy resin. It was cut into two plates at the epoxy resin boundary. One embedded in epoxy resin was further cut to examine the cross section of the

(a)

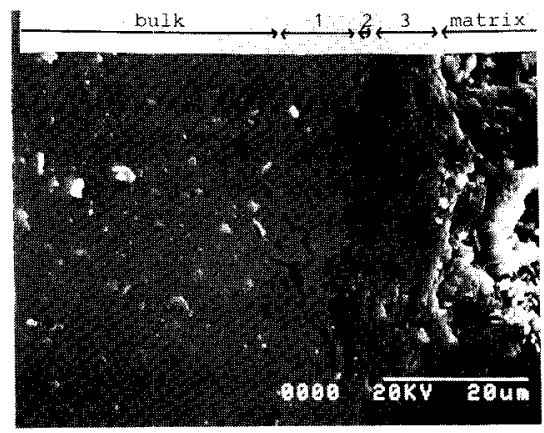

(c)

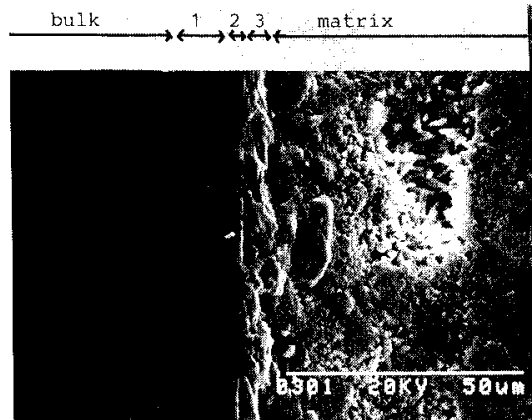

corrosion layer by SEM and EPMA. The other semicircular which was free of epoxy resin was washed in $1 \mathrm{~mol} / \mathrm{dm}^{3} \mathrm{HC} 1$ and water to examine the surface of the separator plate by EPMA and XRD. Concerning one of them, the separator plate exposed to $\mathrm{Li} / \mathrm{K} / \mathrm{Sr}$ for 4000 hours, the corrosion layer was vertically characterized by repeatedly polishing and examining the surface by XRD.

\section{RESULTS AND DISCUSSION} 3.1 Corrosivity of the carbonates to SUS $310 \mathrm{~S}$ in wet seal region on the oxidizing gas side

We used the thickness of the corrosion layer (TCL) as a measure of the corrosivity of the carbonate mixtures. The cross sections of corrosion layers of the separator plate exposed to $\mathrm{Li} / \mathrm{K}$, $\mathrm{Li} / \mathrm{K} / \mathrm{Ca}, \mathrm{Li} / \mathrm{K} / \mathrm{Sr}$ and $\mathrm{Li} / \mathrm{K} / \mathrm{Ba}$ for 4000 hours at the wet seal region are shown in Fig. 3. The elemental dot mapping of $\mathrm{Li} / \mathrm{K} / \mathrm{Sr}$ are shown in Figure 4 as representative. All samples in Figure 3 gave the same dot patterns as Fig. 4. The presence of $\mathrm{Ca}, \mathrm{Sr}$ and $\mathrm{Ba}$ in the carbonate

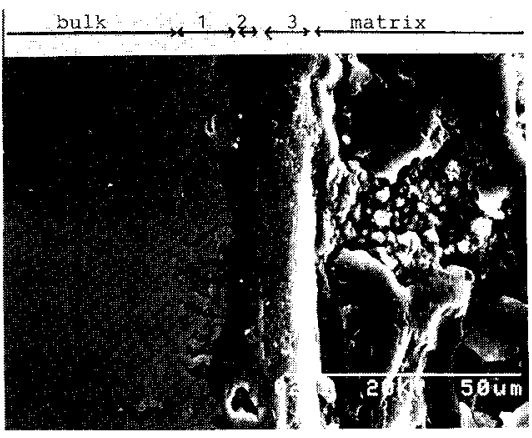

(b)

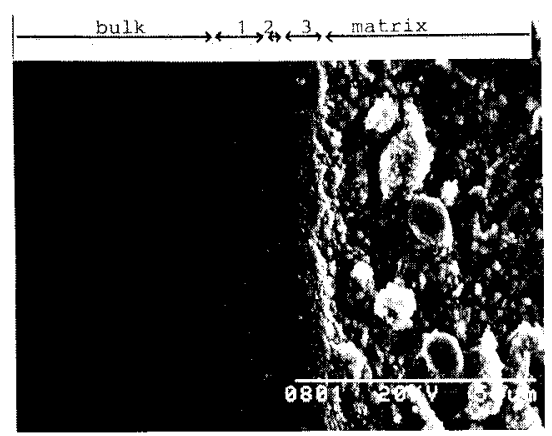

(d)

Fig. 3 SEM micrographs of the corrosion layer of the separator plate exposed to (a) $\mathrm{Li} / \mathrm{K}$, (b) $\mathrm{Li} / \mathrm{K} / \mathrm{Ca}$, (c) $\mathrm{Li} / \mathrm{K} / \mathrm{Sr}$ and (d) $\mathrm{Li} / \mathrm{K} / \mathrm{Ba}$ in 4000 -hour test. The corrosion layer assignment is shown at the top and was derived from the result of the EPMA; 1 . inner layer, 2. second layer and 3. outer layer. 
(a)

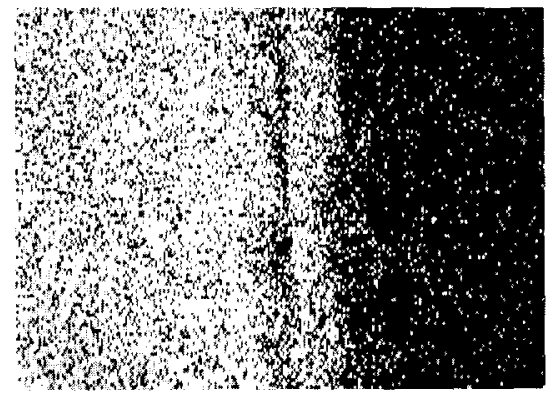

(b)

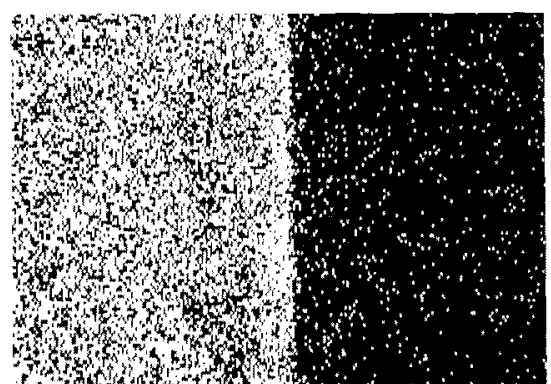

(c)

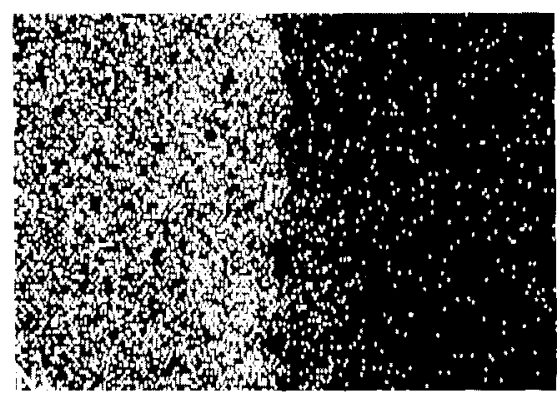

mixture did not affect the elemental maps. The corrosion layer was defined as the layer of which composition was different from that of bulk metal, based on the result of EPMA. TCLs, which were measured using the SEM micrographs and the EPMA mappings, are plotted in Fig. 5. Figure 5 shows that TCLs at the wet seal region do not have significant difference. The effect of the addition of $\mathrm{Ca}, \mathrm{Sr}$ and $\mathrm{Ba}$ to $\mathrm{Li} / \mathrm{K}$ and $\mathrm{Li} / \mathrm{Na}$ on the corrosivity to SUS 310 S was not found to be significant.

\subsection{Corrosion of SUS $310 \mathrm{~S}$ in the wet seal} region on the oxidizing gas side

Figure 3 and 4 show that the corrosion layer of the separator plate exposed to $\mathrm{Li} / \mathrm{K} / \mathrm{Sr}$ consists of three layers. These three layers were also observed on all other sample plates. The EPMA result of the cross section of the corrosion layer of (d)

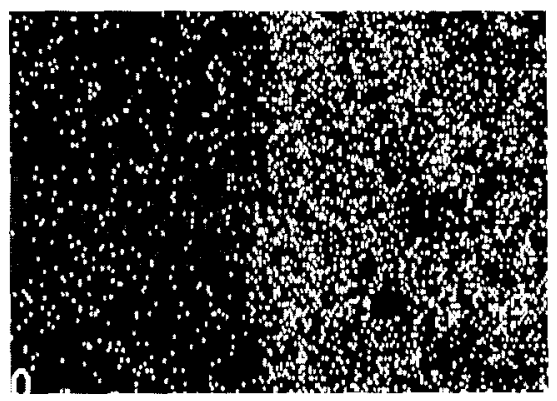

(e)

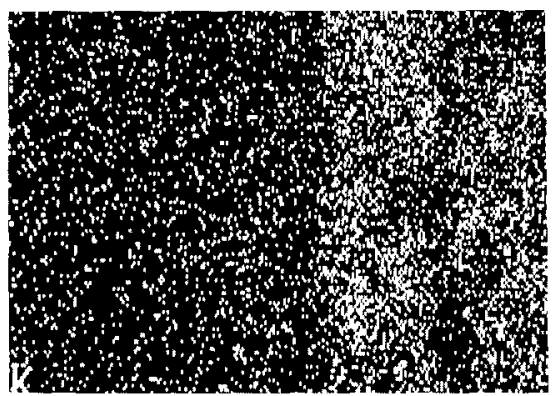

Fig. 4 Elemental dot mapping of Fig. 3 (c) of the separator plate exposed to $\mathrm{Li} / \mathrm{K} / \mathrm{Sr}$. (a) $\mathrm{Fe}$, (b) $\mathrm{Cr}$, (c) $\mathrm{Ni}$, (d) $\mathrm{O}$ and (e) $\mathrm{K}$.

(a)

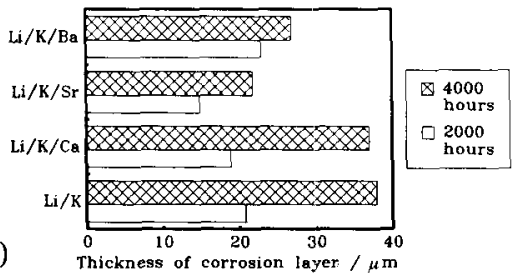

(b)

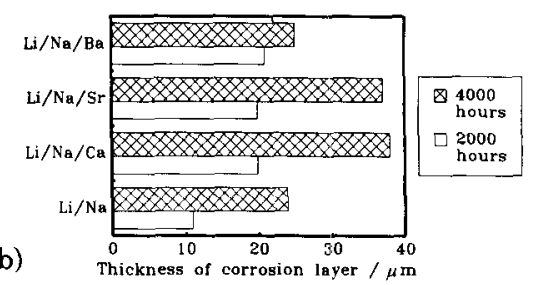

Fig. 5 The thickness of corrosion layer in wet seal region. $\mathrm{Li} / \mathrm{K}$ host system is shown in (a). Li/Na host system is shown in (b).

all samples is shown in Table 3.

For the sample exposed to $\mathrm{Li} / \mathrm{K} / \mathrm{Sr}$ for 4000 hours the vertical characterization of the corrosion layers by XRD is shown in Table 4 . Since the thin corrosion layer easily transmitted X-ray, the XRD results sometimes involved the com- 
Table 3 EPMA result of cross section of corrosion layer.

\begin{tabular}{|c|c|c|}
\hline Corrosion layer & Major element & Minor element \\
\hline Outer layer & $\mathrm{Fe}, \mathrm{K}$ or $\mathrm{Na}^{*}, \mathrm{O}$ & $\mathrm{Ni}$ \\
\hline Second layer & $\mathrm{Cr}, \mathrm{O}$ & \\
\hline Inner layer & $\mathrm{Fe}, \mathrm{Ni}, \mathrm{Cr}^{* *}$ & $\mathrm{O}^{* *}$ \\
\hline
\end{tabular}

pound of the inside layer. In fact, although the characterization on the surface shows that there is $\mathrm{LiCrO}_{2}$ as a minor compound, it is due to the reflection of that in the inner layer. The identification of the corrosion layer was considered with the XRD and the EPMA results. In Table 4, the depth of the polished surface do not correspond the structure of three layers.

On the surface of all washed sample plates, iron and nickel were observed as major and minor elements by EPMA, respectively. $\mathrm{LiFeO}_{2}$ was identified as a major compound on the wet seal surface of all washed sample plates based on the results of XRD as shown in Table 4. Since oxygen was distributed in the outer and the second layer as shown in Table 3, the corrosion products of these layers were metal oxides. The major oxide found in the outer layer was $\mathrm{LiFeO}_{2}$, while the minor oxide of the outer layer was expected to be a nickel oxide. From the result of the cross section analysis of the unwashed sample plates in Table 3, the present potassium in the outer layer came from $\mathrm{K}_{2} \mathrm{CO}_{3}$. It can be seen in Figure 4(e) as representative. It is found that the outer layer have a porous structure. Table 3 and 4 indicate that the second layer is mainly consisted of $\mathrm{LiCrO}_{2}$ and $\mathrm{Cr}_{2} \mathrm{O}_{3}$. The second layer near the outer layer was seemed to be mainly consisted of $\mathrm{LiCrO}_{2}$ from Table 4. It is reasonable that $\mathrm{Li}_{2} \mathrm{CO}_{3}$ penetrated into the porous outer layer and the chromium oxide yield $\mathrm{LiCrO}_{2}$. Table 3 shows that oxygen does not seem to be present in the inner layer. For example it can be seen in Fig. 4(d). Figure 6 shows the SEM micrograph of a dark wedge shape area in the inner layer of Fig. 3(a). The EPMA result suggests that in this
Table 4 Detected compounds of the corrosion layer on SUS $310 \mathrm{~S}$ exposed to Li/K/Sr by XRD. The surface of sample plate was polished in a $\mathrm{SiC}$ paper to remove the corrosion layer and examined by XRD.

\begin{tabular}{|c|c|c|}
\hline & Major compound & Minor compound \\
\hline Surface & $\mathrm{LiFeO}_{2}$ & $\mathrm{LiCrO}_{2}$ \\
\hline First & $\mathrm{LiCrO}_{2}$ & $\mathrm{Cr}_{2} \mathrm{O}_{3}, \mathrm{LiFeO}_{2}$ \\
\hline Second & $\mathrm{LiCrO}_{2}, \mathrm{Cr}_{2} \mathrm{O}_{3}$ & $\mathrm{LiFeO}_{2}, \mathrm{SUS} 310 \mathrm{~S}$ \\
\hline Finish & SUS $310 \mathrm{~S}$ & \\
\hline
\end{tabular}

dark area chromium oxide compound is dominant. Since the content of oxygen in the inner layer was very low, the white area in Fig. 6 was the chromium - depletion metal area.

Based on the above results, the schematic diagram of corrosion layer is shown in Fig. 7. The results of SEM micrographs and EPMA mappings suggest that the second layer $\left(\mathrm{LiCrO}_{2}\right.$ and $\left.\mathrm{Cr}_{2} \mathrm{O}_{3}\right)$ is compact. The compact layer would act as a barrier to further corrosion of the SUS $310 \mathrm{~S}$ underneath the compact layer. This may be the reason there was not significant difference in the TCLs for the different carbonate mixtures.

The application of the parabolic rate law to the growth of the corrosion layer might be useful for the evaluation of the dynamic behavior of the corrosion. The dynamic behavior of corrosion of SUS $310 \mathrm{~S}$ in the different carbonate mixtures under the oxidizing gas is shown in Fig. 8. The apparent parabolic rate constant, $\mathrm{Kp}$, is estimated from Figure 8 as following.

$$
0.24<\mathrm{Kp} / \mu \mathrm{m} / \mathrm{h}^{1 / 2}<0.52
$$

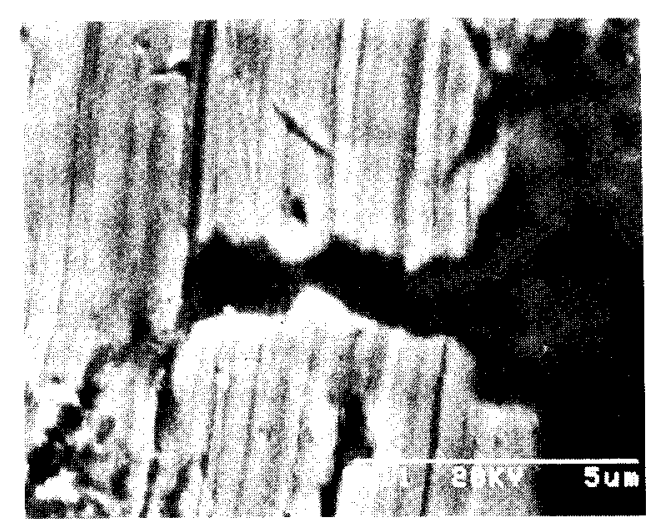

Fig. 6 The magnification of Fig. 3 (a). 


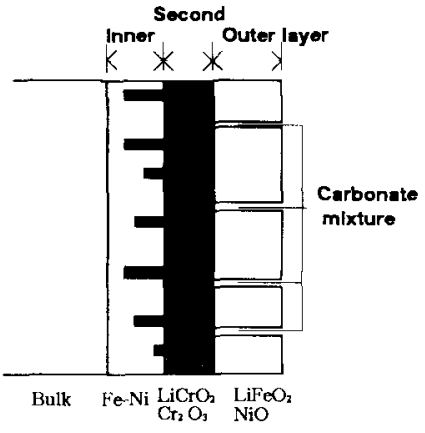

Fig. 7 The schematic diagram of the corrosion layer.

The constant for SUS 310 S under the oxidizing gas in the typical molten carbonate mixture was reported to be $\left.0.35 \mu \mathrm{m} / \mathrm{h}^{1 / 2} 8,9\right)$. The apparent parabolic rate constant obtained in the present work is in agreement with the literature values. This estimation was obtained without considering the difference of the compositions of carbonate mixtures. This result may suggest that the dynamic behavior of corrosion of SUS 310 S does not depend on the composition of the carbonate mixtures.

\section{CONCLUSION}

The effect of addition of alkaline earth carbonate to the electrolyte of the MCFC was investigated from the viewpoint of corrosivity of the molten carbonate mixtures to SUS $310 \mathrm{~S}$ under an oxidizing gas. In this work, the dual atmosphere method to simulate the environment of separator plate in MCFC was adapted. The thickness of the corrosion layer in the wet seal region was used as a measure of the corrosivity.

Considering the corrosivity to SUS $310 \mathrm{~S}$ which is typically used for the separator plate, there were not significant differences obtained with different carbonate mixtures. Since these alternative carbonates do not corrode SUS $310 \mathrm{~S}$ any more than the typical carbonate used in the MCFC, the addition of alkaline earth carbonate is recommended from the viewpoint of the lower solubility of nickel oxide.

The structure of the corrosion layer of SUS $310 \mathrm{~S}$, which consists of three layers, is independ ent of kinds of carbonate mixtures. The results of

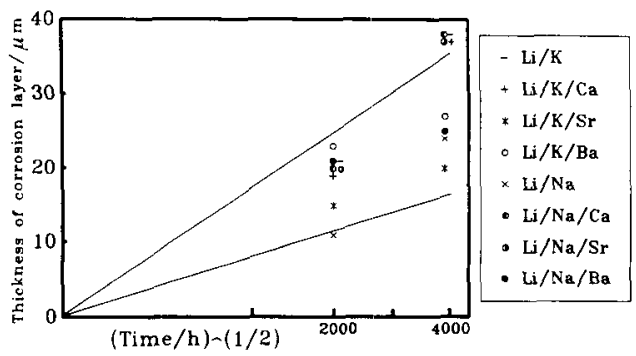

Fig. 8 The growth of corrosion layer as a function of time. The relation of TCLs $(h)$ and time $(t)$ was applied for the equation: $h=\mathrm{Kp}^{*} t^{1 / 2} . \mathrm{Kp}$ is a parabolic rate low constant.

SEM and EPMA of corrosion layers show that the second layer $\left(\mathrm{LiCrO}_{2}\right.$ and $\left.\mathrm{Cr}_{2} \mathrm{O}_{3}\right)$ is compact. This layer prevents the molten carbonates from corroding the inner layer. This compact structure could be the reason there are not significant differences in the corrosivity of different carbonate mixtures.

\section{REFERENCES}

1) K. Tanimoto, Y. Miyazaki, M. Yanagida, S. Tanase, T. Kojima, N. Ohtori, H. Okuyama and T. Kodama, Dennki Kagaku, 59, 619 (1991).

2) E.J. Vesely, Jr., Corrosion of Materials in Molten Carbonate Fuel Cells (MCFC), Final report of IIT Research Institute to U.S. Department of Energy on Contract DE-AC21-86MC23265, March (1990).

3) (a). K. Nakagawa, Testu to Hagane, 75, 1852 (1989). (b). K. Nakagawa, Bosyoku Gijutu, 37, 473 (1988).

4) K. Hiyama, Bosyoku Gijutu, 39, 409 (1990).

5) R.A. Donado, L.G. Marianowski, H.C. Maru and J.R. Selman, J. Electrochem. Soc., 131, 2535 (1984).

6) R.A. Donado, L.G. Marianowski, H.C. Maru and J.R. Selman, J.Electrochem.Soc., 131, 2541 (1984).

7) A. Pigeaud, C.Y. Yuh and P. Singh, Corrosion Resistant Materials in MCFC Environment, Final Report of Energy Research Corporation to U.S. Department of Energy on Contract DEAC21-84MC21186, (1987).

8) A.J. Appelby, F.R. Foulkes, Fuel Cell Handbook, Van Nostrand Reinhold, New York, p.560 (1989).

9) C.Y. Yuh and A. Pigeaud, Determination of Optimum Electrolyte Composition for Molten Carbonate Fuel Cells, Final Report of Energy Research Corporation to U. S. Department of Energy on Contract DE-AC21-86MC23264, June (1989). 